DOI: 10.12731/2658-4034-2020-3-62-68

\title{
ПРОЕКТИРОВАНИЕ ПЕДАГОГИЧЕСКОЙ СИСТЕМЫ В УСЛОВИЯХ РЕАЛИЗАЦИИ КОМПЕТЕНТНОСТНОГО ПОДХОДА
}

\author{
Шехмирзова А.М., Грибина Л.В.
}

ФГБОУ ВО «Адыгейский государственный университет»,

г. Майкоп, Республика Адыгея, Российская Федерация

В статье рассматривается педагогическая технология как проект педагогической системы, реализуемой на практике. Раскрываются сущностные характеристики педагогической системыл. Подчеркивается необходимость поиска новой педагогической технологии в исторически развивающейся педагогической системе.

Ключевые слова: педагогическая система; педагогическая технология; педагогическая задача; компетентностный подход; содержание образования.

\section{DESIGNING A PEDAGOGICAL SYSTEM IN THE CONTEXT OF IMPLEMENTING A COMPETENCY-BASED APPROACH}

\section{Shekhmirzova A.M., Gribina L.V.}

Adyghe State University, Maikop, Adygea Republic, Russian Federation

The article considers pedagogical technology as a project of the pedagogical system, implemented in practice. The essential characteristics of the pedagogical system are revealed. The necessity of searching for a new pedagogical technology in a historically developing pedagogical system is emphasized. 
Keywords: pedagogical system; pedagogical technology; pedagogical task; competency-based approach; content of education.

Понятие «педагогическая технология» зародившись более трех десятилетий назад в США, Англии постепенно вошел в лексикон педагогики и в настоящее время распространилось практически во всех странах мира. Однако на сегодняшний день отсутствует единое понимание этого термина. В литературе можно встретить более 300 формулировок в зависимости от того, как авторы представляют структуру и составляющие технологического процесса.

Наибольший интерес для нашего исследования представляет определение педагогической технологии, предложенное академиком В.П. Беспалько. Он под педагогической технологией понимает «проект определенной педагогической системы, реализуемый на практике» [1]. Поскольку основным признаком педагогической технологии является его целенаправленность, то данное определение может быть переосмыслено в следующей трактовке: «педагогическая технология - это проект определенной педагогической системы, в котором педагог реализует спроектированный дидактический процесс, гарантирующий достижение образовательных целей». Отсюда под педагогической системой (ПС) можно понимать социально обусловленную целостность взаимосвязанных компонентов и взаимодействующих между собой и окружающей средой участников дидактического процесса, направленная на формирование личности с социально заданными качествами. Инвариантными компонентами любой педагогической системы, возникающих на разных исторических этапов общественного развития, являются: цели образования, содержание образования, субъекты образовательного процесса (педагог и учащиеся), методы обучения, организационные формы, средства обучения и протекающие дидактические процессы.

Любое образовательное учреждение может рассматриваться как сложная социальная педагогическая система. Она характеризуется открытостью, поскольку между нею и окружающей действительностью происходят непрерывные информационные процессы. 
Педагогическая система является элементом системы образования, оказывающей влияние на ее постоянную изменчивость.

На основе анализа литературных источников нами выделены ряд общих характеристик, которым обладает педагогическая система $[2 ; 3]$ :

1) По происхождению она имеет реальный характер,

2) По субстанциональному признаку характеризуется социальностью,

3) По степени сложности носит сложный характер,

4) По характеру взаимодействия с внешней средой является открытой,

5) По признаку изменчивости имеет динамический характер,

6) По наличию цели характеризуется целеустремленностью,

7) По признаку управляемости обладает самоуправляемым характером,

8) По наличию целеустремленности и динамичности обладает развивающимися свойствами,

9) По результативности взаимодействующих компонентов характеризуется системностью как интегративного качества, которым не обладает ни один из отдельно взятых элементов,

10) По наличию преемственности обладает историчностью, связями прошлого, настоящего и будущего всех ее компонентов и системы в целом.

Педагогическая система имеет вход и выход.

Вход определяет взаимодействие всех компонентов, благодаря соединению которых протекает дидактический процесс.

Выход определяет результат этого процесса, который может иметь основной и побочный продукт. Основной связан с формированием личности с социально заданными компетентными качествами, а побочный отражает незапланированный и неуправляемый результат.

Благодаря целеустремленности и управлению в ПС создается обратная связь, обеспечивающая соответствие между фактическим входом и желаемым выходом. Качество результативности функционирования ПС определяется соответствием входа и выхода. Цели 
как системообразующий компонент ПС соотносятся с результатами, образуя замкнутый цикл.

На входе цели формирования личности с заданными качествами определяются ценностными ориентациями конкретного исторического общества. Для современного общества наиболее востребованными являются личностные качества, формируемые в виде компетентностей. При изменении цели должна измениться и ПС. Ограничения, накладываемые на функционирование ПС, определяются совокупностью норм и правил, устанавливаемых требованиями системы образования. Полнота совпадения цели с результатами служит надежным критерием эффективности функционирования всех структурных компонентов ПС. Поэтому все компоненты ПС объединяются единым управлением.

ПС проектируется компетентными лицами и в ее рамках реализуется дидактический процесс. Проектирование ПС основывается на принципе структурной и содержательной целостности, предполагающий достижение гармоничного взаимодействия всех инвариантных компонентов. Соотношение между компонентами всегда должно быть равновесным, чтобы при любом изменении в ПС, их противодействующие силы были тождественно уравновешены. Например, при изменении средств обучения, в качестве которого вводится компьютер, должны в такой же степени быть преобразованы все другие компоненты, чтобы получилась качественно новая, обладающая интегративными свойствами ПС. Такое качество приводит к необходимости поиска новой более совершенной педагогической технологии, вычерпывающей все дидактические возможности компьютера. Такая необходимость в появлении педагогической технологии возникла в Адыгейском государственном университете, где в рамках учебного процесса на очном отделении факультета естествознания, реализуется дистанционное обучение по системе Moodle. Этот программный продукт постепенно осваиваемый педагогическим коллективом университета удобен для создания курсов дисциплин и web-сайтов, базирующиеся в internet. Нахождение педагогической технологии для реализации требований современ- 
ного ФГОС по направлению подготовки Педагогическое образование (бакалавр).

Подобные изменения, происходящие исторически, связаны с эволюционным развитием ПС, в ходе которого в ней возникают педагогические явления, находящие свое объяснение в структурных сдвигах ее компонентов, преобразовании их свойств, качеств и характера связей между ними. Из-за открытости ПС, ее связей с практикой в ней наблюдается несоответствие между целями и результатами. Это приводит к нарушению в ней равновесности компонентов. Сильное воздействие на ПС оказывают внешние социально-экономические, политические, технологические факторы. В итоге в ней наступает порог неустойчивости и она со своими структурными компонентами выходит из состояния равновесности. Вернуться к прежнему устойчивому, равновесному состоянию становится уже не возможным. Привычный и хорошо отлаженный механизм в новых изменившихся условиях прекращает действовать. Отсюда возникает практическая необходимость в проектировании новой ПС. Существенно такая потребность наблюдается при изменении целей образования. Так, изменившиеся цели образования в соответствии с современной педагогической парадигмой привели к ситуации, при которой налаженный механизм традиционной системы образования больше не имеет эффективности для реализации компетентностного подхода в соответствии с новым поколением ФГОС. Если не будет спроектирована новая педагогическая система, то это приведет к несовпадению запланированных целей в виде компетентностей и получаемых результатов, что не будет оправдывать социальные ожидания: на выходе из ПС окажутся не подготовленные к изменившимся социально-экономическим условиям специалисты. Чтобы исключить или свести к минимуму подобные несоответствия педагогическая наука должна разработать новый проект ПС, которая позволит с наименьшими издержками в изменившихся условиях достичь максимального совпадения целей и результатов педагогической деятельности на основе компетентностного подхода. 
Так исторически происходит непрерывное развитие ПС благодаря неразрывной взаимосвязи науки и практики. При этом каждый раз возникает необходимость в соответствии с достигнутым научнотехническим прогрессом поиска новых педагогических технологий, которые позволяют адекватно решать поставленные педагогические задачи. Основной педагогической задачей в соответствии с требованиями современного ФГОС высшей школы является реализация компетентностного подхода к содержанию образования.

Педагогическая задача в структуре ПС отображает цель, достижение которой обусловлено современными условиями и располагаемой информацией для деятельности педагогического коллектива как субъектов образовательного процесса. В рамках педагогической задачи цель связана с формированием социально заданных качеств личности обучаемых в виде компетентностей, условия отражают исходные личностные качества студентов, а информация предполагает содержание реализуемых учебных дисциплин и оказываемого посредством них воспитательного влияния.

Каждая педагогическая задача разрешима с помощью адекватной технологии, целостность которой обеспечивается взаимосвязанной разработкой и использованием методов, организационных форм и средств обучения. Результат решения педагогической задачи с помощью технологии связан с протекающим дидактическим процессом, который определяет алгоритмы функционирования и управления в ПС.

Точному воспроизведению на практике найденной педагогической технологии в спроектированной ПС, адекватно решающей педагогические задачи, способствует гармонично управляемый и реализуемый дидактический процесс, который функционирует на основе педагогических закономерностей и принципов обучения. Они устанавливают нормы организации образовательного процесса в целом для реализации содержания образования как единого конструкта посредством учебных дисциплин. Закономерности и принципы обучения определяют, каким образом добиться целей формирования личности с заданными качествами, какими нормативными положе- 
ниями при этом руководствоваться. Педагогическая технология при точном воспроизведении ее на практике любым педагогом может гарантировать успех педагогической деятельности на основе последовательного осуществления системы дидактических принципов как руководящих практических положений.

\section{Список литературы}

1. Беспалько В.П. Слагаемые педагогической технологии. М.: Педагогика, 1989. 192 с.

2. Кларин М.В. Педагогическая технология в учебном процессе. Анализ зарубежного опыта. М.: Знание, 1989. 80 с.

3. Чернилевский Д.В. Дидактические технологии в высшей школе. М.: ЮНИТИ-ДАНА, 2002. 437 с.

\section{References}

1. Bespal'ko V.P. Slagaemye pedagogicheskoy tekhnologii. M.: Pedagogika, 1989. $192 \mathrm{~s}$.

2. Klarin M.V. Pedagogicheskaya tekhnologiya v uchebnom protsesse. Analiz zarubezhnogo opyta. M.: Znanie, 1989. $80 \mathrm{~s}$.

3. Chernilevskiy D.V. Didakticheskie tekhnologii v vysshey shkole. M.: YuNITI-DANA, 2002. $437 \mathrm{~s}$. 